\title{
Generalized autocommuting probability of a finite group relative to its subgroups
}

\author{
Parama Dutta (iD, Rajat Kanti Nath*(D) \\ Department of Mathematical Sciences, Tezpur University, Napaam-784028, Sonitpur, Assam, India
}

\begin{abstract}
Let $H \subseteq K$ be two subgroups of a finite group $G$ and $\operatorname{Aut}(K)$ the automorphism group of $K$. In this paper, we consider the generalized autocommuting probability of $G$ relative to its subgroups $H$ and $K$, denoted by $\operatorname{Pr}_{g}(H, \operatorname{Aut}(K))$, which is the probability that the autocommutator of a randomly chosen pair of elements, one from $H$ and the other from $\operatorname{Aut}(K)$, is equal to a given element $g \in K$. We study several properties as well as obtain several computing formulae of this probability. As applications of the computing formulae, we also obtain several bounds for $\operatorname{Pr}_{g}(H, \operatorname{Aut}(K))$ and characterizations of some finite groups through $\operatorname{Pr}_{g}(H, \operatorname{Aut}(K))$.
\end{abstract}

Mathematics Subject Classification (2010). 20D60, 20P05, 20F28

Keywords. automorphism group, autocommuting probability, autoisoclinism

\section{Introduction}

Let $G$ be a finite group acting on a set $\Omega$. Let $\operatorname{Pr}(G, \Omega)$ denotes the probability that a randomly chosen element of $\Omega$ fixes a randomly chosen element of $G$. In 1975, Sherman [13] initiated the study of $\operatorname{Pr}(G, \Omega)$ considering $G$ to be an abelian group and $\Omega=\operatorname{Aut}(G)$, the automorphism group of $G$. Note that

$$
\operatorname{Pr}(G, \operatorname{Aut}(G))=\frac{|\{(x, \alpha) \in G \times \operatorname{Aut}(G):[x, \alpha]=1\}|}{|G||\operatorname{Aut}(G)|}
$$

where $[x, \alpha]$ is the autocommutator of $x$ and $\alpha$ defined as $x^{-1} \alpha(x)$. The ratio $\operatorname{Pr}(G, \operatorname{Aut}(G))$ is called autocommuting probability of $G$. The case when $G$ is non-abelian is considered in $[1,3,12]$. Few generalizations of $\operatorname{Pr}(G, \operatorname{Aut}(G))$ can also be found in $[3,4,9,12]$.

Let $H$ and $K$ be two subgroups of $G$ such that $H \subseteq K$. We define

$$
\operatorname{Pr}_{g}(H, \operatorname{Aut}(K))=\frac{|\{(x, \alpha) \in H \times \operatorname{Aut}(K):[x, \alpha]=g\}|}{|H||\operatorname{Aut}(K)|}
$$

where $g \in K$. That is, $\operatorname{Pr}_{g}(H, \operatorname{Aut}(K))$ is the probability that the autocommutator of a randomly chosen pair of elements, one from $H$ and the other from $\operatorname{Aut}(K)$, is equal to a given element $g \in K$. The ratio $\operatorname{Pr}_{g}(H, \operatorname{Aut}(K))$ is called generalized autocommuting probability of $G$ relative to its subgroups $H$ and $K$. Clearly, if $H=G$ and $g=1$ then $\operatorname{Pr}_{g}(H, \operatorname{Aut}(K))=\operatorname{Pr}(G, \operatorname{Aut}(G))$. Note that the cases when $H=G$ and $K=G$

\footnotetext{
*Corresponding Author.

Email addresses: parama@gonitsora.com (P. Dutta), rajatkantinath@yahoo.com (R.K. Nath)

Received: 26.06.2018; Accepted: 16.12.2018
} 
are considered in [3] and [4], respectively. If we replace $\operatorname{Aut}(K)$ by $\operatorname{Inn}(K)$, the inner automorphism group of $K$, in (1.1) then $\operatorname{Pr}_{g}(H, \operatorname{Inn}(K))=\operatorname{Pr}_{g}(H, K)$ where

$$
\operatorname{Pr}_{g}(H, K)=\frac{\left|\left\{(x, y) \in H \times K: x^{-1} y^{-1} x y=g\right\}\right|}{|H||K|}
$$

which is introduced and studied in [2]. In this paper, we study several properties as well as obtain several computing formulae of $\operatorname{Pr}_{g}(H$, Aut $(K))$. We also obtain some bounds for $\operatorname{Pr}_{g}(H, \operatorname{Aut}(K))$ and characterize some finite groups through $\operatorname{Pr}_{g}(H, \operatorname{Aut}(K))$ as applications.

We write $S(H, \operatorname{Aut}(K))$ to denote the set $\{[x, \alpha]: x \in H$ and $\alpha \in \operatorname{Aut}(K)\}$ and $[H, \operatorname{Aut}(K)]:=\langle S(H, \operatorname{Aut}(K))\rangle$. We also write $L(H, \operatorname{Aut}(K)):=\{x \in H:[x, \alpha]=$ 1 for all $\alpha \in \operatorname{Aut}(K)\}$ and $L(G):=L(G$, Aut $(G))$, the absolute center of $G$ (see [6]). Note that $L(H, \operatorname{Aut}(K))$ is a normal subgroup of $H$ contained in $H \cap Z(K)$. Further, $L(H, \operatorname{Aut}(K))=\bigcap_{\alpha \in \operatorname{Aut}(K)} C_{H}(\alpha)$, where $C_{H}(\alpha)=\{x \in H:[x, \alpha]=1\}$ is a subgroup of $H$. Let $C_{\operatorname{Aut}(K)}(x):=\{\alpha \in \operatorname{Aut}(K): \alpha(x)=x\}$ for $x \in H$ and $C_{\operatorname{Aut}(K)}(H)=$ $\{\alpha \in \operatorname{Aut}(K): \alpha(x)=x$ for all $x \in H\}$. Then $C_{\operatorname{Aut}(K)}(x)$ is a subgroup of $\operatorname{Aut}(K)$ and $C_{\operatorname{Aut}(K)}(H)=\bigcap_{x \in H} C_{\operatorname{Aut}(K)}(x)$. We consider the action of $\operatorname{Aut}(K)$ on $K$ given by $(\alpha, x) \mapsto \alpha(x)$ where $\alpha \in \operatorname{Aut}(K)$ and $x \in K$. Let $\operatorname{orb}_{K}(x):=\{\alpha(x): \alpha \in \operatorname{Aut}(K)\}$ be the orbit of $x \in K$. Then by orbit-stabilizer theorem, we have

$$
\left|\operatorname{orb}_{K}(x)\right|=\frac{|\operatorname{Aut}(K)|}{\left|C_{\operatorname{Aut}(K)}(x)\right|} .
$$

Clearly, $\operatorname{Pr}_{g}(H, \operatorname{Aut}(K))=1$ if and only if $[H, \operatorname{Aut}(K)]=\{1\}$ and $g=1$ if and only if $H=L(H, \operatorname{Aut}(K))$ and $g=1$. Also, $\operatorname{Pr}_{g}(H, \operatorname{Aut}(K))=0$ if and only if $g \notin S(H, \operatorname{Aut}(K))$. Therefore, we consider $H \neq L(H, \operatorname{Aut}(K))$ and $g \in S(H, \operatorname{Aut}(K))$ throughout the paper.

\section{Some properties}

We begin with the following lower bounds.

Proposition 2.1. Let $H$ and $K$ be two subgroups of a finite group $G$ such that $H \subseteq K$ and $g \in K$.

(a) If $g=1$ then

$$
\operatorname{Pr}_{g}(H, \operatorname{Aut}(K)) \geq \frac{|L(H, \operatorname{Aut}(K))|}{|H|}+\frac{\left|C_{\operatorname{Aut}(K)}(H)\right|(|H|-|L(H, \operatorname{Aut}(K))|)}{|H||\operatorname{Aut}(K)|} .
$$

(b) If $g \neq 1$ then $\operatorname{Pr}_{g}(H, \operatorname{Aut}(K)) \geq \frac{|L(H, \operatorname{Aut}(K))|\left|C_{\operatorname{Aut}(K)}(H)\right|}{|H||\operatorname{Aut}(K)|}$.

Proof. Let $\mathcal{C}$ denotes the set $\{(x, \alpha) \in H \times \operatorname{Aut}(K):[x, \alpha]=g\}$.

If $g=1$ then we have $S:=(L(H, \operatorname{Aut}(K)) \times \operatorname{Aut}(K)) \cup\left(H \times C_{\operatorname{Aut}(K)}(H)\right)$ is a subset of $\mathcal{C}$. We also have

$$
|S|=|L(H, \operatorname{Aut}(K))||\operatorname{Aut}(K)|+\left|C_{\operatorname{Aut}(K)}(H)\right||H|-|L(H, \operatorname{Aut}(K))|\left|C_{\operatorname{Aut}(K)}(H)\right| .
$$

Therefore,

$$
\begin{aligned}
\operatorname{Pr}_{g}(H, \operatorname{Aut}(K)) \geq & \frac{1}{|H||\operatorname{Aut}(K)|}\{|L(H, \operatorname{Aut}(K))||\operatorname{Aut}(K)|+ \\
& \left.\left|C_{\operatorname{Aut}(K)}(H)\right||H|-|L(H, \operatorname{Aut}(K))|\left|C_{\text {Aut }(K)}(H)\right|\right\}
\end{aligned}
$$

and hence part (a) follows.

Now we consider the case when $g \neq 1$. Since $g \in S(H$, Aut $(K))$ we have $\mathcal{C}$ is nonempty. Let $(y, \beta) \in \mathcal{C}$ then $(y, \beta) \notin L(H, \operatorname{Aut}(K)) \times C_{\operatorname{Aut}(K)}(H)$ otherwise $[y, \beta]=1$. It is easy to see that the coset $(y, \beta)\left(L(H, \operatorname{Aut}(K)) \times C_{\operatorname{Aut}(K)}(H)\right)$ is a subset of $\mathcal{C}$ having or$\operatorname{der}|L(H, \operatorname{Aut}(K))|\left|C_{\operatorname{Aut}(K)}(H)\right|$. Therefore, $|\mathcal{C}| \geq|L(H, \operatorname{Aut}(K))|\left|C_{\operatorname{Aut}(K)}(H)\right|$ and hence part (b) follows. 
Proposition 2.2. Let $H$ and $K$ be two subgroups of a finite group $G$ such that $H \subseteq K$. If $g \in K$ then

$$
\operatorname{Pr}_{g^{-1}}(H, \operatorname{Aut}(K))=\operatorname{Pr}_{g}(H, \operatorname{Aut}(K)) .
$$

Proof. Let $X$ and $Y$ denote the sets $\{(x, \alpha) \in H \times \operatorname{Aut}(K):[x, \alpha]=g\}$ and $\{(y, \beta) \in$ $\left.H \times \operatorname{Aut}(K):[y, \beta]=g^{-1}\right\}$, respectively. Consider the mapping $f: X \rightarrow Y$ given by $f((x, \alpha))=\left(\alpha(x), \alpha^{-1}\right)$. Since $f$ is bijective, we have $|X|=|Y|$. Hence, the result follows from (1.1).

Proposition 2.3. Let $G_{1}$ and $G_{2}$ be two finite groups. Let $H_{1}, K_{1}$ and $H_{2}, K_{2}$ be subgroups of $G_{1}$ and $G_{2}$ respectively such that $H_{1} \subseteq K_{1}, H_{2} \subseteq K_{2}$ and $\operatorname{gcd}\left(\left|K_{1}\right|,\left|K_{2}\right|\right)=1$. If $\left(g_{1}, g_{2}\right) \in K_{1} \times K_{2}$ then

$$
\operatorname{Pr}_{\left(g_{1}, g_{2}\right)}\left(H_{1} \times H_{2}, \operatorname{Aut}\left(K_{1} \times K_{2}\right)\right)=\operatorname{Pr}_{g_{1}}\left(H_{1}, \operatorname{Aut}\left(K_{1}\right)\right) \operatorname{Pr}_{g_{2}}\left(H_{2}, \operatorname{Aut}\left(K_{2}\right)\right) .
$$

Proof. Let $X$ denotes the set

$$
\left\{\left((x, y), \alpha_{K_{1} \times K_{2}}\right) \in\left(H_{1} \times H_{2}\right) \times \operatorname{Aut}\left(K_{1} \times K_{2}\right):\left[(x, y), \alpha_{K_{1} \times K_{2}}\right]=\left(g_{1}, g_{2}\right)\right\} .
$$

Also, let $Y$ and $Z$ denote the sets $\left\{\left(x, \alpha_{K_{1}}\right) \in H_{1} \times \operatorname{Aut}\left(K_{1}\right):\left[x, \alpha_{K_{1}}\right]=g_{1}\right\}$ and $\left\{\left(y, \alpha_{K_{2}}\right) \in H_{2} \times \operatorname{Aut}\left(K_{2}\right):\left[y, \alpha_{K_{2}}\right]=g_{2}\right\}$, respectively. Since $\operatorname{gcd}\left(\left|K_{1}\right|,\left|K_{2}\right|\right)=1$, by [7, Lemma 2.1], we have $\operatorname{Aut}\left(K_{1} \times K_{2}\right)=\operatorname{Aut}\left(K_{1}\right) \times \operatorname{Aut}\left(K_{2}\right)$. Therefore, for every $\alpha_{K_{1} \times K_{2}} \in \operatorname{Aut}\left(K_{1} \times K_{2}\right)$ there exist unique $\alpha_{K_{1}} \in \operatorname{Aut}\left(K_{1}\right)$ and $\alpha_{K_{2}} \in \operatorname{Aut}\left(K_{2}\right)$ such that $\alpha_{K_{1} \times K_{2}}=\alpha_{K_{1}} \times \alpha_{K_{2}}$, where $\alpha_{K_{1}} \times \alpha_{K_{2}}((x, y))=\left(\alpha_{K_{1}}(x), \alpha_{K_{2}}(y)\right)$ for all $(x, y) \in H_{1} \times H_{2}$. Also, for all $(x, y) \in H_{1} \times H_{2}$, we have $\left[(x, y), \alpha_{K_{1} \times K_{2}}\right]=\left(g_{1}, g_{2}\right)$ if and only if $\left[x, \alpha_{K_{1}}\right]=g_{1}$ and $\left[y, \alpha_{K_{2}}\right]=g_{2}$. These show that $X=Y \times Z$. Therefore

$$
\frac{|X|}{\left|H_{1} \times H_{2}\right|\left|\operatorname{Aut}\left(K_{1} \times K_{2}\right)\right|}=\frac{|Y|}{\left|H_{1}\right|\left|\operatorname{Aut}\left(K_{1}\right)\right|} \cdot \frac{|Z|}{\left|H_{2}\right|\left|\operatorname{Aut}\left(K_{2}\right)\right|} .
$$

Hence, the result follows from (1.1).

In the year 1940, Hall [5] introduced the concept of isoclinism between two groups. Following Hall, Moghaddam et al. [8] have defined autoisoclinism between two groups, in the year 2013. Recall that two groups $G_{1}$ and $G_{2}$ are said to be autoisoclinic if there exist isomorphisms $\psi: \frac{G_{1}}{L\left(G_{1}\right)} \rightarrow \frac{G_{2}}{L\left(G_{2}\right)}, \beta:\left[G_{1}, \operatorname{Aut}\left(G_{1}\right)\right] \rightarrow\left[G_{2}, \operatorname{Aut}\left(G_{2}\right)\right]$ and $\gamma: \operatorname{Aut}\left(G_{1}\right) \rightarrow$ $\operatorname{Aut}\left(G_{2}\right)$ such that the following diagram commutes

$$
\begin{aligned}
& \frac{G_{1}}{L\left(G_{1}\right)} \times \operatorname{Aut}\left(G_{1}\right) \stackrel{\psi \times \gamma}{\longrightarrow} \frac{G_{2}}{L\left(G_{2}\right)} \times \operatorname{Aut}\left(G_{2}\right) \\
& \downarrow a_{\left(G_{1}, \operatorname{Aut}\left(G_{1}\right)\right)} \quad \downarrow a_{\left(G_{2}, \operatorname{Aut}\left(G_{2}\right)\right)} \\
& {\left[G_{1}, \operatorname{Aut}\left(G_{1}\right)\right] \stackrel{\beta}{\longrightarrow}\left[G_{2}, \operatorname{Aut}\left(G_{2}\right)\right]}
\end{aligned}
$$

where the maps $a_{\left(G_{i}, \operatorname{Aut}\left(G_{i}\right)\right)}: \frac{G_{i}}{L\left(G_{i}\right)} \times \operatorname{Aut}\left(G_{i}\right) \rightarrow\left[G_{i}, \operatorname{Aut}\left(G_{i}\right)\right]$, for $i=1,2$, are given by

$$
a_{\left(G_{i}, \operatorname{Aut}\left(G_{i}\right)\right)}\left(x_{i} L\left(G_{i}\right), \alpha_{i}\right)=\left[x_{i}, \alpha_{i}\right] .
$$

Such a pair $(\psi \times \gamma, \beta)$ is called an autoisoclinism between the groups $G_{1}$ and $G_{2}$. We generalize the notion of autoisoclinism in the following way:

Let $H_{1}, K_{1}$ and $H_{2}, K_{2}$ be subgroups of the groups $G_{1}$ and $G_{2}$ respectively. The pairs of subgroups $\left(H_{1}, K_{1}\right)$ and $\left(H_{2}, K_{2}\right)$ such that $H_{1} \subseteq K_{1}$ and $H_{2} \subseteq K_{2}$ are said to be autoisoclinic if there exist isomorphisms $\psi: \frac{H_{1}}{L\left(H_{1}, \text { Aut } K_{1}\right)} \rightarrow \frac{H_{2}}{L\left(H_{2}, \operatorname{Aut}\left(K_{2}\right)\right)}, \beta:\left[H_{1}, \operatorname{Aut}\left(K_{1}\right)\right] \rightarrow$ $\left[H_{2}, \operatorname{Aut}\left(K_{2}\right)\right]$ and $\gamma: \operatorname{Aut}\left(K_{1}\right) \rightarrow \operatorname{Aut}\left(K_{2}\right)$ such that the following diagram commutes

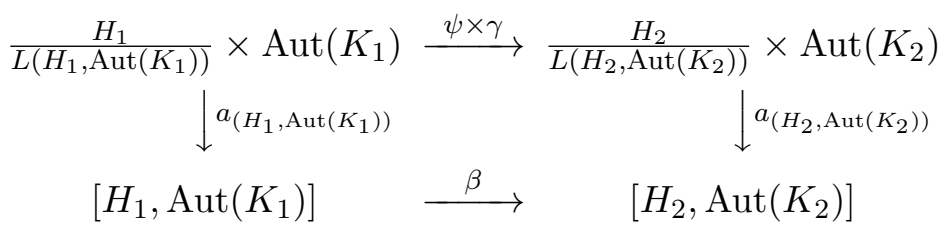


where the maps $a_{\left(H_{i}, \operatorname{Aut}\left(K_{i}\right)\right)}: \frac{H_{i}}{L\left(H_{i}, \operatorname{Aut}\left(K_{i}\right)\right)} \times \operatorname{Aut}\left(K_{i}\right) \rightarrow\left[H_{i}, \operatorname{Aut}\left(K_{i}\right)\right]$, for $i=1,2$, are given by

$$
a_{\left(H_{i}, \operatorname{Aut}\left(K_{i}\right)\right)}\left(x_{i} L\left(H_{i}, \operatorname{Aut}\left(K_{i}\right)\right), \alpha_{i}\right)=\left[x_{i}, \alpha_{i}\right] .
$$

Such a pair $(\psi \times \gamma, \beta)$ is said to be an autoisoclinism between the pairs of groups $\left(H_{1}, K_{1}\right)$ and $\left(H_{2}, K_{2}\right)$. We conclude this section with the following generalization of [3, Theorem 5.1] and [12, Lemma 2.5].

Theorem 2.4. Let $G_{1}$ and $G_{2}$ be two finite groups with subgroups $H_{1}, K_{1}$ and $H_{2}, K_{2}$ respectively such that $H_{1} \subseteq K_{1}$ and $H_{2} \subseteq K_{2}$. If $(\psi \times \gamma, \beta)$ is an autoisoclinism between the pairs $\left(H_{1}, K_{1}\right)$ and $\left(H_{2}, K_{2}\right)$ then, for $g \in K_{1}$,

$$
\operatorname{Pr}_{g}\left(H_{1}, \operatorname{Aut}\left(K_{1}\right)\right)=\operatorname{Pr}_{\beta(g)}\left(H_{2}, \operatorname{Aut}\left(K_{2}\right)\right) .
$$

Proof. Let us consider the sets $\mathcal{S}_{g}=\left\{\left(x_{1} L\left(H_{1}, \operatorname{Aut}\left(K_{1}\right)\right), \alpha_{1}\right) \in \frac{H_{1}}{L\left(H_{1}, \operatorname{Aut}\left(K_{1}\right)\right)} \times \operatorname{Aut}\left(K_{1}\right)\right.$ : $\left.\left[x_{1}, \alpha_{1}\right]=g\right\}$ and $\mathcal{T}_{\beta(g)}=\left\{\left(x_{2}, \alpha_{2}\right) \in \frac{H_{2}}{L\left(H_{2}, \operatorname{Aut}\left(K_{2}\right)\right)} \times \operatorname{Aut}\left(K_{2}\right):\left[x_{2} L\left(H_{2}, \operatorname{Aut}\left(K_{2}\right)\right), \alpha_{2}\right]=\right.$ $\beta(g)\}$. Since $\left(H_{1}, K_{1}\right)$ is autoisoclinic to $\left(H_{2}, K_{2}\right)$ we have $\left|\mathcal{S}_{g}\right|=\left|\mathcal{T}_{\beta(g)}\right|$. Again, it is clear that

and

$$
\left|\left\{\left(x_{1}, \alpha_{1}\right) \in H_{1} \times \operatorname{Aut}\left(K_{1}\right):\left[x_{1}, \alpha_{1}\right]=g\right\}\right|=\left|L\left(H_{1}, \operatorname{Aut}\left(K_{1}\right)\right)\right|\left|\mathcal{S}_{g}\right|
$$

$$
\left|\left\{\left(x_{2}, \alpha_{2}\right) \in H_{2} \times \operatorname{Aut}\left(K_{2}\right):\left[x_{2}, \alpha_{2}\right]=\beta(g)\right\}\right|=\left|L\left(H_{2}, \operatorname{Aut}\left(K_{2}\right)\right)\right|\left|\mathcal{T}_{\beta(g)}\right| .
$$

Hence, the result follows from (1.1), (2.1) and (2.2).

\section{Computing formulae and applications}

For any $x \in H$, let us define the set $T_{x, g}(H, K)=\{\alpha \in \operatorname{Aut}(K):[x, \alpha]=g\}$, where $g$ is a fixed element of $K$. Note that $T_{x, 1}(H, K)=C_{\text {Aut }(K)}(x)$. Also, $T_{x, g}(H, K)$ is non-empty if and only if $x g \in \operatorname{orb}_{K}(x)$. We have the following useful lemma.

Lemma 3.1. Let $H$ and $K$ be two subgroups of a finite group $G$ such that $H \subseteq K$. If $T_{x, g}(H, K)$ is non-empty then $T_{x, g}(H, K)=\mu C_{\operatorname{Aut}(K)}(x)$ for some $\mu \in T_{x, g}(H, K)$ and hence $\left|T_{x, g}(H, K)\right|=\left|C_{\text {Aut }(G)}(x)\right|$.

Proof. Assume that $T_{x, g}(H, K)$ is non-empty. Let $\mu$ be an element of $T_{x, g}(H, K)$. If $\nu \in \mu C_{\operatorname{Aut}(K)}(x)$ then $\nu=\mu \alpha$ for some $\alpha \in C_{\operatorname{Aut}(K)}(x)$. We have

$$
[x, \nu]=[x, \mu \alpha]=x^{-1} \mu(\alpha(x))=[x, \mu]=g
$$

which implies $\nu \in T_{x, g}(H, K)$. Hence, $\mu C_{\text {Aut }(K)}(x) \subseteq T_{x, g}(H, K)$.

If $\gamma \in T_{x, g}(H, K)$ then $\gamma(x)=x g$. We have $\mu^{-1} \gamma(x)=\mu^{-1}(x g)=x$ which implies $\mu^{-1} \gamma \in C_{\operatorname{Aut}(K)}(x)$. Therefore, $\gamma \in \mu C_{\text {Aut }(K)}(x)$ and so $T_{x, g}(H, K) \subseteq \mu C_{\text {Aut }(K)}(x)$. Hence, $T_{x, g}(H, K)=\mu C_{\operatorname{Aut}(K)}(x)$.

The following theorem gives two computing formulae for $\operatorname{Pr}_{g}(H, \operatorname{Aut}(K))$.

Theorem 3.2. Let $H$ and $K$ be two subgroups of a finite group $G$ such that $H \subseteq K$. If $g \in K$ then

$$
\begin{aligned}
\operatorname{Pr}_{g}(H, \operatorname{Aut}(K)) & =\frac{1}{|H||\operatorname{Aut}(K)|} \sum_{\substack{x \in H \\
x g \in \operatorname{orb}_{K}(x)}}\left|C_{\text {Aut }(K)}(x)\right| \\
& =\frac{1}{|H|} \sum_{\substack{x \in H \\
x g \in \operatorname{orb}_{K}(x)}} \frac{1}{\left|\operatorname{orb}_{K}(x)\right|}
\end{aligned}
$$


Proof. Clearly $\{(x, \alpha) \in H \times \operatorname{Aut}(K):[x, \alpha]=g\}=\cup_{x \in H}\left(\{x\} \times T_{x, g}(H, K)\right.$. Since for any two distinct elements $x, y \in H$ the sets $\left.\{x\} \times T_{x, g}(H, K)\right)$ and $\{y\} \times T_{y, g}(H, K)$ are disjoint, we have

$$
|H||\operatorname{Aut}(K)| \operatorname{Pr}_{g}(H, \operatorname{Aut}(K))=\left|\cup_{x \in H}\left(\{x\} \times T_{x, g}(H, K)\right)\right|=\sum_{x \in H}\left|T_{x, g}(H, K)\right| .
$$

Hence, the result follows from Lemma 3.1 and (1.2) noting that $T_{x, g}(H, K) \neq \emptyset$ if and only if $x g \in \operatorname{orb}_{K}(x)$.

Considering $g=1$ in Theorem 3.2, we get the following computing formulae for the ratio $\operatorname{Pr}(H, \operatorname{Aut}(K))$.

Corollary 3.3. Let $H$ and $K$ be two subgroups of a finite group $G$ such that $H \subseteq K$. Then

$$
\operatorname{Pr}(H, \operatorname{Aut}(K))=\frac{1}{|H||\operatorname{Aut}(K)|} \sum_{x \in H}\left|C_{\operatorname{Aut}(K)}(x)\right|=\frac{\left|\operatorname{orb}_{K}(H)\right|}{|H|}
$$

where $\operatorname{orb}_{K}(H)=\left\{\operatorname{orb}_{K}(x): x \in H\right\}$.

Corollary 3.4. Let $H$ and $K$ be two subgroups of a finite group $G$ such that $H \subseteq K$. If $C_{\mathrm{Aut}(K)}(x)=\{I\}$ for all $x \in H \backslash\{1\}$, where $I$ is the identity element of $\operatorname{Aut}(K)$, then

$$
\operatorname{Pr}(H, \operatorname{Aut}(K))=\frac{1}{|H|}+\frac{1}{|\operatorname{Aut}(K)|}-\frac{1}{|H||\operatorname{Aut}(K)|} .
$$

Proof. By Corollary 3.3, we have

$$
|H||\operatorname{Aut}(K)| \operatorname{Pr}(H, \operatorname{Aut}(K))=\sum_{x \in H}\left|C_{\operatorname{Aut}(K)}(x)\right|=|\operatorname{Aut}(K)|+|H|-1 .
$$

Hence, the result follows.

Note that the fact $|\{(x, \alpha) \in H \times \operatorname{Aut}(K):[x, \alpha]=1\}|=\sum_{\alpha \in \operatorname{Aut}(K)}\left|C_{H}(\alpha)\right|$ also gives the following computing formula

$$
\operatorname{Pr}(H, \operatorname{Aut}(K))=\frac{1}{|H||\operatorname{Aut}(K)|} \sum_{\alpha \in \operatorname{Aut}(K)}\left|C_{H}(\alpha)\right| .
$$

In the remaining part of this section, we shall discuss some applications of the computing formulae obtained above. More precisely, we shall obtain some bounds for $\operatorname{Pr}_{g}(H, \operatorname{Aut}(K))$ as well as some characterizations of finite groups in terms of $\operatorname{Pr}_{g}(H, \operatorname{Aut}(K))$. We begin with the following upper bound.

Proposition 3.5. Let $H$ and $K$ be two subgroups of a finite group $G$ such that $H \subseteq K$. If $g \in K$ then

$$
\operatorname{Pr}_{g}(H, \operatorname{Aut}(K)) \leq \operatorname{Pr}(H, \operatorname{Aut}(K)) .
$$

The equality holds if and only if $g=1$.

Proof. Using Theorem 3.2, we have

$$
\begin{aligned}
\operatorname{Pr}_{g}(H, \operatorname{Aut}(K)) & =\frac{1}{|H||\operatorname{Aut}(K)|} \sum_{\substack{x \in H \\
x g \in \operatorname{orb}_{K}(x)}}\left|C_{\operatorname{Aut}(K)}(x)\right| \\
& \leq \frac{1}{|H||\operatorname{Aut}(K)|} \sum_{x \in H}\left|C_{\operatorname{Aut}(K)}(x)\right|=\operatorname{Pr}(H, \operatorname{Aut}(K)) .
\end{aligned}
$$

The equality holds if and only if $x g \in \operatorname{orb}_{K}(x)$ for all $x \in H$ if and only if $g=1$. 
Corollary 3.6. Let $H$ and $K$ be two subgroups of a finite group $G$ such that $H \subseteq K$. Then

$$
\operatorname{Pr}_{g}(H, \operatorname{Aut}(K)) \leq \operatorname{Pr}_{1}(H, K) .
$$

Proof. By [2, Theorem 2.3], we have

$$
\operatorname{Pr}_{1}(H, K)=\frac{1}{|H|} \sum_{x \in H} \frac{1}{\left|\mathrm{cl}_{K}(x)\right|}
$$

where $\operatorname{cl}_{K}(x)=\{\alpha(x): \alpha \in \operatorname{Inn}(K)\}$. Since $\operatorname{cl}_{K}(x) \subseteq \operatorname{orb}_{K}(x)$ for all $x \in H$, we have

$$
\sum_{x \in H} \frac{1}{\left|\operatorname{cl}_{K}(x)\right|} \geq \sum_{x \in H} \frac{1}{\left|\operatorname{orb}_{K}(x)\right|} .
$$

Therefore, by Theorem 3.2, we have $\operatorname{Pr}(H$, Aut $(K)) \leq \operatorname{Pr}_{1}(H, K)$. Hence, the result follows from Proposition 3.5.

Proposition 3.7. Let $H$ and $K$ be two subgroups of a finite group $G$ such that $H \subseteq K$. Let $g \in K$ and $p$ the smallest prime dividing $|\operatorname{Aut}(K)|$. If $g \neq 1$ then

$$
\operatorname{Pr}_{g}(H, \operatorname{Aut}(K)) \leq \frac{|H|-|L(H, \operatorname{Aut}(K))|}{p|H|}<\frac{1}{p} .
$$

Proof. For $x \in L(H, \operatorname{Aut}(K))$ we have $x g \notin \operatorname{orb}_{K}(x)$. Therefore, by Theorem 3.2,

$$
\operatorname{Pr}_{g}(H, \operatorname{Aut}(K))=\frac{1}{|H|} \sum_{\substack{x \in H \backslash L\left(H, \operatorname{Aut}_{(K))} \\ x g \in \operatorname{orb}_{K}(x)\right.}} \frac{1}{\left|\operatorname{orb}_{K}(x)\right|} .
$$

If $x \in H \backslash L(H, \operatorname{Aut}(K))$ and $x g \in \operatorname{orb}_{K}(x)$ then $\left|\operatorname{orb}_{K}(x)\right|>1$. Also $\left|\operatorname{orb}_{K}(x)\right| \operatorname{divides}$ $|\operatorname{Aut}(K)|$ and so $\left|\operatorname{orb}_{K}(x)\right| \geq p$. Hence, the result follows from (3.1).

Proposition 3.8. Let $H_{1}, H_{2}$ and $K$ be subgroups of a finite group $G$ such that $H_{1} \subseteq$ $H_{2} \subseteq K$. Then

$$
\operatorname{Pr}_{g}\left(H_{1}, \operatorname{Aut}(K)\right) \leq\left|H_{2}: H_{1}\right| \operatorname{Pr}_{g}\left(H_{2}, \operatorname{Aut}(K)\right) .
$$

The equality holds if and only if $x g \notin \operatorname{orb}_{K}(x)$ for all $x \in H_{2} \backslash H_{1}$.

Proof. By Theorem 3.2, we have

$$
\begin{aligned}
\left|H_{1}\right||\operatorname{Aut}(K)| \operatorname{Pr}_{g}\left(H_{1}, \operatorname{Aut}(K)\right) & =\sum_{\substack{x \in H_{1} \\
x g \in \operatorname{orb}_{K}(x)}}\left|C_{\operatorname{Aut}(K)}(x)\right| \\
& \leq \sum_{\substack{x \in H_{2} \\
x g \in \operatorname{orb}_{K}(x)}}\left|C_{\operatorname{Aut}(K)}(x)\right| \\
& =\left|H_{2}\right||\operatorname{Aut}(K)| \operatorname{Pr}_{g}\left(H_{2}, \operatorname{Aut}(K)\right) .
\end{aligned}
$$

Hence, the result follows.

Proposition 3.9. Let $H$ and $K$ be two subgroups of a finite group $G$ such that $H \subseteq K$. If $g \in K$ then

$$
\operatorname{Pr}_{g}(H, \operatorname{Aut}(K)) \leq|K: H| \operatorname{Pr}(K, \operatorname{Aut}(K))
$$

with equality if and only if $g=1$ and $H=K$.

Proof. By Proposition 3.5, we have

$$
\begin{aligned}
\operatorname{Pr}_{g}(H, \operatorname{Aut}(K)) & \leq \operatorname{Pr}(H, \operatorname{Aut}(K)) \\
& =\frac{1}{|H||\operatorname{Aut}(K)|} \sum_{x \in H}\left|C_{\operatorname{Aut}(K)}(x)\right| \\
& \leq \frac{1}{|H||\operatorname{Aut}(K)|} \sum_{x \in K}\left|C_{\operatorname{Aut}(K)}(x)\right| .
\end{aligned}
$$


Hence, the result follows from Corollary 3.3.

Theorem 3.10. Let $H$ and $K$ be two subgroups of a finite group $G$ such that $H \subseteq K$ and $p$ the smallest prime dividing $|\operatorname{Aut}(K)|$. Then

$$
\operatorname{Pr}(H, \operatorname{Aut}(K)) \geq \frac{|L(H, \operatorname{Aut}(K))|}{|H|}+\frac{p\left(|H|-\left|X_{H}\right|-|L(H, \operatorname{Aut}(K))|\right)+\left|X_{H}\right|}{|H||\operatorname{Aut}(K)|}
$$

and

$$
\operatorname{Pr}(H, \operatorname{Aut}(K)) \leq \frac{(p-1)|L(H, \operatorname{Aut}(K))|+|H|}{p|H|}-\frac{\left|X_{H}\right|(|\operatorname{Aut}(K)|-p)}{p|H||\operatorname{Aut}(K)|},
$$

where $X_{H}=\left\{x \in H: C_{\operatorname{Aut}(K)}(x)=\{I\}\right\}$.

Proof. Since $X_{H} \cap L(H, \operatorname{Aut}(K))=\emptyset$ we have

$$
\begin{aligned}
\sum_{x \in H}\left|C_{\operatorname{Aut}(K)}(x)\right|= & \left|X_{H}\right|+|\operatorname{Aut}(K)||L(H, \operatorname{Aut}(K))| \\
& +\sum_{x \in H \backslash\left(X_{H} \cup L(H, \operatorname{Aut}(K))\right)}\left|C_{\operatorname{Aut}(K)}(x)\right| .
\end{aligned}
$$

Also $\{I\} \neq C_{\operatorname{Aut}(K)}(x) \neq \operatorname{Aut}(K)$ and so $p \leq\left|C_{\operatorname{Aut}(K)}(x)\right| \leq \frac{|\operatorname{Aut}(K)|}{p}$ for $x \in H \backslash\left(X_{H} \cup\right.$ $L(H, \operatorname{Aut}(K)))$. Therefore

$$
\begin{aligned}
\sum_{x \in H}\left|C_{\operatorname{Aut}(K)}(x)\right| \geq & \left|X_{H}\right|+|\operatorname{Aut}(K)||L(H, \operatorname{Aut}(K))| \\
& +p\left(|H|-\left|X_{H}\right|-|L(H, \operatorname{Aut}(K))|\right)
\end{aligned}
$$

and

$$
\begin{aligned}
\sum_{x \in H}\left|C_{\text {Aut }(K)}(x)\right| \leq & \left|X_{H}\right|+|\operatorname{Aut}(K)||L(H, \operatorname{Aut}(K))| \\
& +\frac{|\operatorname{Aut}(K)|\left(|H|-\left|X_{H}\right|-|L(H, \operatorname{Aut}(K))|\right)}{p} .
\end{aligned}
$$

Hence, the result follows from Corollary 3.3, (3.2) and (3.3).

Following two theorems give characterizations of $H$ in terms of $\operatorname{Pr}(H, \operatorname{Aut}(K))$.

Theorem 3.11. Let $H \subseteq K$ be two subgroups of a finite group $G$.

(a) If $p$ and $q$ are the smallest primes dividing $|\operatorname{Aut}(K)|$ and $|H|$ respectively then $\operatorname{Pr}(H, \operatorname{Aut}(K)) \leq \frac{p+q-1}{p q}$. In particular, if $p=q$ then $\operatorname{Pr}(H, \operatorname{Aut}(K)) \leq \frac{2 p-1}{p^{2}} \leq \frac{3}{4}$.

(b) If $\operatorname{Pr}(H, \operatorname{Aut}(K))=\frac{p+q-1}{p q}$, for some primes $p$ and $q$, then $p q$ divides $|H||\operatorname{Aut}(K)|$. Further, if $p$ and $q$ are the smallest primes dividing $|\operatorname{Aut}(K)|$ and $|H|$ respectively, then $\frac{H}{L(H, \operatorname{Aut}(K))} \cong \mathbb{Z}_{q}$. In particular, if $H$ and $\operatorname{Aut}(K)$ are of even order and $\operatorname{Pr}(H, \operatorname{Aut}(K))=\frac{3}{4}$ then $\frac{H}{L(H, \operatorname{Aut}(K))} \cong \mathbb{Z}_{2}$.

Proof. (a) Since $H \neq L(H, \operatorname{Aut}(K))$ we have $|H: L(H, \operatorname{Aut}(K))| \geq q$. Therefore, by Theorem 3.10, we have

$$
\operatorname{Pr}(H, \operatorname{Aut}(K)) \leq \frac{1}{p}\left(\frac{p-1}{|H: L(H, \operatorname{Aut}(K))|}+1\right) \leq \frac{p+q-1}{p q} .
$$

(b) Using (1.1), we have $(p+q-1)|H||\operatorname{Aut}(K)|=p q|\{(x, \alpha) \in H \times \operatorname{Aut}(K):[x, \alpha]=1\}|$. Since $p q$ does not divide $(p+q-1), p q$ divides $|H||\operatorname{Aut}(K)|$.

If $p$ and $q$ are the smallest primes dividing $|\operatorname{Aut}(K)|$ and $|H|$ respectively then, by Theorem 3.10, we have

$$
\frac{p+q-1}{p q} \leq \frac{1}{p}\left(\frac{p-1}{|H: L(H, \operatorname{Aut}(K))|}+1\right)
$$


which gives $|H: L(H, \operatorname{Aut}(K))| \leq q$. Hence, $\frac{H}{L(H, \operatorname{Aut}(K))} \cong \mathbb{Z}_{q}$.

Theorem 3.12. Let $H \subseteq K$ be two subgroups of a finite group $G$.

(a) If $p, q$ are the smallest primes dividing $|\operatorname{Aut}(K)|$ and $|H|$ respectively and $H$ is nonabelian then $\operatorname{Pr}(H, \operatorname{Aut}(K)) \leq \frac{q^{2}+p-1}{p q^{2}}$. In particular, if $p=q$ then $\operatorname{Pr}(H, \operatorname{Aut}(K)) \leq$ $\frac{p^{2}+p-1}{p^{3}} \leq \frac{5}{8}$.

(b) If $H$ is non-abelian and $\operatorname{Pr}(H, \operatorname{Aut}(K))=\frac{q^{2}+p-1}{p q^{2}}$, for some primes $p$ and $q$, then $p q$ divides $|H||\operatorname{Aut}(K)|$. Further, if $p$ and $q$ are the smallest primes dividing $|\operatorname{Aut}(K)|$ and $|H|$ respectively then $\frac{H}{L(H, \operatorname{Aut}(K))} \cong \mathbb{Z}_{q} \times \mathbb{Z}_{q}$. In particular, if $H$ and $\operatorname{Aut}(K)$ are of even order and $\operatorname{Pr}(H, \operatorname{Aut}(K))=\frac{5}{8}$ then $\frac{H}{L(H, \operatorname{Aut}(K))} \cong \mathbb{Z}_{2} \times \mathbb{Z}_{2}$.

Proof. (a) Since $H$ is non-abelian we have $|H: L(H, \operatorname{Aut}(K))| \geq q^{2}$. Therefore, by Theorem 3.10, we have

$$
\operatorname{Pr}(H, \operatorname{Aut}(K)) \leq \frac{1}{p}\left(\frac{p-1}{|H: L(H, \operatorname{Aut}(K))|}+1\right) \leq \frac{q^{2}+p-1}{p q^{2}} .
$$

(b) Using (1.1), we have $\left(q^{2}+p-1\right)|H||\operatorname{Aut}(K)|=p q^{2} \mid\{(x, \alpha) \in H \times \operatorname{Aut}(K):[x, \alpha]=$ $1\} \mid$. Since $p q$ does not divide $\left(q^{2}+p-1\right), p q$ divides $|H||\operatorname{Aut}(K)|$.

If $p$ and $q$ are the smallest primes dividing $|\operatorname{Aut}(K)|$ and $|H|$ respectively then, by Theorem 3.10, we have

$$
\frac{q^{2}+p-1}{p q^{2}} \leq \frac{1}{p}\left(\frac{p-1}{|H: L(H, \operatorname{Aut}(K))|}+1\right)
$$

which gives $|H: L(H, \operatorname{Aut}(K))| \leq q^{2}$. Since $H$ is non-abelian we have $|H: L(H, \operatorname{Aut}(K))|$ $\neq 1, q$. Hence, $\frac{H}{L(H, \operatorname{Aut}(K))} \cong \mathbb{Z}_{q} \times \mathbb{Z}_{q}$.

Proposition 3.13. Let $H$ and $K$ be two subgroups of a finite group $G$ such that $H \subseteq$ $K$. Let $p, q$ be the smallest prime divisors of $|\operatorname{Aut}(K)|,|H|$ respectively and $\mid \operatorname{Aut}(K)$ : $C_{\operatorname{Aut}(K)}(x) \mid=p$ for all $x \in H \backslash L(H, \operatorname{Aut}(K))$. Then

$$
\operatorname{Pr}(H, \operatorname{Aut}(K))= \begin{cases}\frac{p+q-1}{p q} & \text { if } \frac{H}{L(H, \operatorname{Aut}(K))} \cong \mathbb{Z}_{q} \\ \frac{q^{2}+p-1}{p q^{2}} & \text { if } \frac{H}{L(H, \operatorname{Aut}(K))} \cong \mathbb{Z}_{q} \times \mathbb{Z}_{q} .\end{cases}
$$

Proof. For all $x \in H \backslash L(H, \operatorname{Aut}(K))$ we have $\left|\operatorname{Aut}(K): C_{\operatorname{Aut}(K)}(x)\right|=p$ and so $\left|C_{\operatorname{Aut}(K)}(x)\right|=\frac{|\operatorname{Aut}(K)|}{p}$. Therefore, by Corollary 3.3, we have

$$
\begin{aligned}
\operatorname{Pr}(H, \operatorname{Aut}(K)) & =\frac{|L(H, \operatorname{Aut}(K))|}{|H|}+\frac{1}{|H||\operatorname{Aut}(K)|} \sum_{x \in H \backslash L(H, \operatorname{Aut}(K))}\left|C_{\operatorname{Aut}(K)}(x)\right| \\
& =\frac{|L(H, \operatorname{Aut}(K))|}{|H|}+\frac{|H|-|L(H, \operatorname{Aut}(K))|}{p|H|} \\
& =\frac{1}{p}\left(\frac{p-1}{|H: L(H, \operatorname{Aut}(K))|}+1\right) .
\end{aligned}
$$

Hence, the result follows.

Note that Proposition 3.13 gives partial converses of Theorems 3.11(b) and 3.12(b). We conclude this paper with the following two lower bounds analogous to the lower bounds obtained in [11, Theorem A] and [10, Theorem 1].

Theorem 3.14. Let $H$ and $K$ be two subgroups of a finite group $G$ such that $H \subseteq K$. Then

$$
\operatorname{Pr}(H, \operatorname{Aut}(K)) \geq \frac{1}{|S(H, \operatorname{Aut}(K))|}\left(1+\frac{|S(H, \operatorname{Aut}(K))|-1}{|H: L(H, \operatorname{Aut}(K))|} .\right.
$$


The equality holds if and only if $\operatorname{orb}_{K}(x)=x S(H, \operatorname{Aut}(K))$ for all $x \in H \backslash L(H, \operatorname{Aut}(K))$.

Proof. We have $\mu(x)=x[x, \mu] \in x S(H, \operatorname{Aut}(K))$ for all $x \in H \backslash L(H, \operatorname{Aut}(K))$ and $\mu \in \operatorname{Aut}(K)$. Therefore, for all $x \in H \backslash L(H, \operatorname{Aut}(K))$ we have $\operatorname{orb}_{K}(x) \subseteq x S(H, \operatorname{Aut}(K))$ and so $\left|\operatorname{orb}_{K}(x)\right| \leq|S(H, \operatorname{Aut}(K))|$. Using Corollary 3.3, we have

$$
\begin{aligned}
\operatorname{Pr}(H, \operatorname{Aut}(K)) & =\frac{1}{|H|}\left(\sum_{x \in L(H, \operatorname{Aut}(K))} \frac{1}{\left|\operatorname{orb}_{K}(x)\right|}+\sum_{x \in H \backslash L(H, \operatorname{Aut}(K))} \frac{1}{\left|\operatorname{orb}_{K}(x)\right|}\right) \\
& \geq \frac{|L(H, \operatorname{Aut}(K))|}{|H|}+\frac{1}{|H|} \sum_{x \in H \backslash L(H, \operatorname{Aut}(K))} \frac{1}{|S(H, \operatorname{Aut}(K))|} .
\end{aligned}
$$

Hence, the result follows.

Corollary 3.15. Let $H$ and $K$ be two subgroups of a finite group $G$ such that $H \subseteq K$. Then

$$
\operatorname{Pr}(H, \operatorname{Aut}(K)) \geq \frac{1}{|[H, \operatorname{Aut}(K)]|}\left(1+\frac{|[H, \operatorname{Aut}(K)]|-1}{|H: L(H, \operatorname{Aut}(K))|}\right) .
$$

If $H \neq L(H, \operatorname{Aut}(K))$ then the equality holds if and only if $[H, \operatorname{Aut}(K)]=S(H, \operatorname{Aut}(K))$ and $\operatorname{orb}_{K}(x)=x[H, \operatorname{Aut}(K)]$ for all $x \in H \backslash L(H, \operatorname{Aut}(K))$.

Proof. It is easy to see that

$$
\frac{1}{n}\left(1+\frac{n-1}{|H: L(H, \operatorname{Aut}(K))|}\right) \geq \frac{1}{m}\left(1+\frac{m-1}{|H: L(H, \operatorname{Aut}(K))|}\right)
$$

for any two integers $m \geq n$. If $L(H, \operatorname{Aut}(K)) \neq H$ then equality holds in (3.4) if and only if $m=n$. Now, the result follows from Theorem 3.14 and (3.4) since $|[H, \operatorname{Aut}(K)]| \geq$ $|S(H, \operatorname{Aut}(K))|$.

Note that the equality holds if and only if equality holds in Theorem 3.14 and (3.4).

It is worth mentioning that Theorem 3.14 gives better lower bound than the lower bound given by Corollary 3.15. Also

$$
\begin{aligned}
\frac{1}{|[H, \operatorname{Aut}(K)]|}\left(1+\frac{|[H, \operatorname{Aut}(K)]|-1}{|H: L(H, \operatorname{Aut}(K))|}\right) \geq & \frac{|L(H, \operatorname{Aut}(K))|}{|H|} \\
& +\frac{p(|H|-|L(H, \operatorname{Aut}(K))|)}{|H||\operatorname{Aut}(K)|} .
\end{aligned}
$$

Hence, Theorem 3.14 gives better lower bound than the lower bound given by Theorem 3.10 .

Acknowledgment. The authors would like to thank the referee for his/her valuable comments and suggestions.

\section{References}

[1] H. Arora and R. Karan, What is the probability an automorphism fixes a group element?, Comm. Algebra, 45(3), 1141-1150, 2017.

[2] A.K. Das and R.K. Nath, On generalized relative commutativity degree of a finite group, Int. Electron. J. Algebra, 7, 140-151, 2010.

[3] P. Dutta and R.K. Nath, Autocommuting probabilty of a finite group, Comm. Algebra, 46 (3), 961-969, 2018.

[4] P. Dutta and R.K. Nath, On generalized autocommutativity degree of finite groups, Hacet. J. Math. Stat. 48 (2), 472-478, 2019.

[5] P. Hall, The classification of prime power groups, J. Reine Angew. Math. 182, 130$141,1940$.

[6] P.V. Hegarty, The absolute centre of a group, J. Algebra, 169 (3), 929-935, 1994. 
[7] C.J. Hillar and D.L. Rhea, Automorphism of finite abelian groups, Amer. Math. Monthly, 114 (10), 917-923, 2007.

[8] M.R.R. Moghaddam, M.J. Sadeghifard and M. Eshrati, Some properties of autoisoclinism of groups, Fifth International group theory conference, Islamic Azad University, Mashhad, Iran, 13-15 March 2013.

[9] M.R.R. Moghaddam, F. Saeedi and E. Khamseh, The probability of an automorphism fixing a subgroup element of a finite group, Asian-Eur. J. Math. 4 (2), 301-308, 2011.

[10] R.K. Nath and A.K. Das, On a lower bound of commutativity degree, Rend. Circ. Mat. Palermo, 59 (1), 137-142, 2010.

[11] R.K. Nath and M.K. Yadav, Some results on relative commutativity degree, Rend. Circ. Mat. Palermo, 64 (2), 229-239, 2015.

[12] M.R. Rismanchian and Z. Sepehrizadeh, Autoisoclinism classes and autocommutativity degrees of finite groups, Hacet. J. Math. Stat. 44 (4), 893-899, 2015.

[13] G.J. Sherman, What is the probability an automorphism fixes a group element?, Amer. Math. Monthly, 82, 261-264, 1975. 